\title{
Challenges of writing theses and dissertations among postgraduate students in Tanzanian higher learning institutions
}

Komba, Sotco Claudius

Sokoine University of Agriculture, Tanzania (sotratz@yahoo.com)

Received: 25 June 2015

Available Online: 19 November 2015
Revised: 23 September 2015 DOI: $10.5861 /$ ijrse.2015.1280

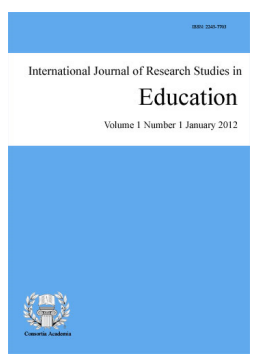

ISSN: 2243-7703 Online ISSN: 2243-7711

Accepted: 2 November 2015

OPEN ACCESS

\section{Abstract}

This study sought to investigate challenges of writing theses and dissertations among postgraduate students. A total of 103 research reports, including 39 theses and 64 dissertations from three universities in Tanzania, were reviewed. The findings indicated that the majority (more than 50\%) of the candidates, whose theses and dissertations were reviewed, faced numerous challenges in writing their theses and dissertations. The candidates seemed to have challenges in writing all chapters which were included in their research reports. The challenges included inappropriateness in presenting different chapters of the reports and lack of academic writing skills. Based on the findings of this study, it is recommended, among others, that research methods courses offered in the universities should be reviewed in terms of contents and teaching approaches in order to overcome the challenges as portrayed by the candidates in the reviewed theses and dissertations.

Keywords: challenges; writing theses and dissertations; higher learning institutions; Tanzania 


\section{Challenges of writing theses and dissertations among postgraduate students in Tanzanian higher learning institutions}

\section{Introduction}

In Tanzanian higher learning institutions, students who pursue Master's degree programmes by coursework have to complete the coursework component of the programme by passing a minimum number of units, including all the prescribed core courses in the programme and proceed to the research phase of the programme. The research phase involves a candidate to generate a topic; to plan and execute a research activity investigating the generated topic; and to write-up a report on what they did and the findings of the study. The report is either called a dissertation for students who pursue the programs by coursework and dissertation and thesis for students whose programs do not involve coursework activities (Sokoine University of Agriculture, 2011; University of Dar es Salaam, 2013).

There have been some worldwide concerns from higher education stakeholders, including external examiners and education quality assurance officers, on the quality of theses and dissertations written and submitted by postgraduate students. Most of the concerns have suggested that the quality of the research reports is low (Wang \& Li, 2008; Bitchener \& Basturkmen, 2006; Holbrook et al., 2004; Lessing \& Schulze, 2003). In Tanzanian context, the review of external examination reports by the author of this article for theses and dissertations in four universities of Tanzania has revealed that one of the recurring comments by the examiners in the reports was on the candidates' weaknesses in presenting different chapters of the theses and dissertations. The weaknesses seemed to be evenly spread into the areas of scope, significance and contribution of the theses and dissertations. As a member of academic staff in one of the Tanzanian universities, the author has been involved in teaching, supervising postgraduate students at both Master's degree and PhD levels, and serving as an external examiner for a good number of students' theses and dissertations in different universities. In the process of interacting with the postgraduate students and examining their research reports, it has become evident that the writing of theses and dissertations has not been an easy task for the majority of the students.

Therefore, the fact that students have been facing challenges in writing their theses and dissertations is indisputable. In spite of the existence of such challenges, there are limited studies which have been conducted to investigate the nature and scope of this phenomenon. Most of the studies conducted worldwide on postgraduate training have focused on issues of supervision (Mapolisa \& Mafa, 2011; Taylor \& Beasley, 2005; Murray, 2002; Hartley \& Jory, 2000). The limited studies on challenges of writing theses or dissertations (Wang \& Li, 2008; Bitchener \& Basturkmen, 2006; Lessing \& Schulze, 2003) have focused on international students pusuing their studies in either the UK or elsewhere, outside the African continent. Therefore, this study was trigered by the limited knowledge on the nature and scope of challenges of writing theses and dissertations facing the majority of postgraduate students in Tanzanian context. Specifically, the study aimed to answer two specific questions:

$>$ To what extent do postgraduate students face challenges in writing their theses or dissertations?

$>$ What should be done in order to alleviate the challenges?

This study was timely as the findings were envisaged to enlighten both students and academic staff in Tanzanian higher learning institutions on issues related to thesis and dissertation writing. Specifically, the findings were expected to serve as baseline information for making recommendations on how best the challenges of writing theses and dissertations facing postgraduate students could be overcome in Tanzanian higher learning institutions. 


\section{Literature review}

Postgraduate training involves students who are registered for postgraduate diploma, master's degree or doctorate. This kind of training introduces individuals to a world of independent research undertakings. As pointed out in the introductory part of this article, the pursuance may take the option of either coursework and dissertation or thesis alone. Whether the students pursue their programs by either coursework and dissertation or thesis, they ought to conduct research and write a report for submission before the registered degree is awarded. The research report is expected to indicate that the student has demonstrated a mastery of the subject area that has been researched. According to Helm (1989), as cited in Lessing and Schulze (2003, p. 159), "postgraduate research pose three problem areas, namely the research design, the data collecting and processing and the report writing". The writing phase of the research report, be it a dissertation or thesis, has been posing a lot of challenges to students. This concurs with what Huang $(2007$, p. 30) writes that "to the vast majority of students, the dissertation is by far the most challenging piece of academic work".

The motives for students to pursue postgraduate studies are varied. For instance Ho et al. (2012) found that students held several motives for studying postgraduate studies. The motives could be classified into categories related to qualifications, current career, potential future career, interest, perpetual students and professional and social networks. In the same light, a study by Brailsford (2010) revealed that improving career prospects, personal development, and intrinsic interest in their discipline were the motives cited by most of the study participants. A similar study was also conducted by Teowkul et al. (2009), who found that the majority of postgraduate students enrolled into the programs in order to gain more respect and compensation, and be able to easily change jobs and make transition into new careers smoothly. However, these motives and aspirations can only be realized upon the successful completion of their studies. One of the requirements for completing the studies is writing a thesis or dissertation, whose challenges were the focus of this study.

The available literature indicates that a good number of studies have been conducted worldwide on either postgraduate supervision or thesis writing challenges. For example, Wang and Li (2008) conducted a study to explore the thesis writing experiences of a small group of international postgraduate research students at one Australian university. In this study, the author sought to identify, among others, the challenges the students faced in their thesis writing process. The findings indicated that the students faced a lot of challenges in their thesis writing which might have emanated from pedagogical shortfalls and lack of intercultural sensitivity in the supervision of students. However, Wang and Linda's study was not done in Tanzanian context, as was the case with the current study. Another similar study was conducted by Cadman (1997) in which it was revealed that the main cause of the challenges that students faced in writing their theses and dissertations could be attributed to different epistemologies in which the students had been trained and in which their identities as learners were rooted.

On the other hand, Mapolisa and Mafa (2011) conducted a study which sought to explore the experiences of supervisors in the supervision of postgraduate students' research. Among the main findings of the study, it was revealed that most students had limitations in the development of proposals. The problems ranged from not knowing what to include in the proposals to the ethical considerations. However, the study did not investigate challenges the candidates faced in writing their theses or dissertations after conducting their studies. In addition, Bitchener and Basturkmen (2006) conducted a study which, among other issues, focused on student difficulties in writing the discussion of results section (DRS) of the thesis. The findings showed that students did not have an adequate understanding of the function of the discussion results sections of their theses. While Bitchener and Basturkmen's study focused on student difficulties in writing the discussion of results section, the current study explored challenges which students faced in writing all sections of their theses or dissertations, in the context of Tanzanian universities. Therefore, deducing from the available literature, it seems that the challenges of writing theses or dissertations are a worldwide phenomenon. However, most of the studies have been conducted in either developed countries or elsewhere outside Tanzania, and limited studies are available, as far as Tanzanian context is concerned. 


\section{Methodology}

This was a qualitative study which employed a documentary research method. In this method, documents that contain information about the phenomenon under investigation are examined (Bailey 1994). The phenomenon in this case was challenges that students face in writing their theses and dissertations. A total of 103 research reports, including 39 theses and 64 dissertations, randomly selected from the libraries of three universities in Tanzania, were analyzed. The review of the documents focused on students' abilities to write appropriately different chapters of the theses and dissertations. Content analysis was used to analyze the theses and dissertations by comparing what the candidates had presented in the documents with the ideal information needed in different chapters of the documents. The criteria used in judging whether or not the different chapters of the theses and dissertations were appropriately written are as presented in Table 1:

\section{Table 1}

Criteria used in reviewing different chapters of theses and dissertations

\begin{tabular}{ll}
\hline \multicolumn{1}{c}{ Chapter } & \multicolumn{1}{c}{ Criteria } \\
\hline Chapter One: & Presentation of theoretical background of the study (indicating what is known and what \\
Background to the & is unknown, hence justifying the candidate's study) \\
Problem & Clearly stated statement of the problem (indicating what had prompted the candidate to \\
& conduct their studies) \\
& Stating specific objectives of the study in line with the main objectives/purposes \\
& Appropriately stated specific objectives of the sudy (indicating what the candidate was \\
& required to do) \\
& The language used is clear and understandable
\end{tabular}

Chapter Two: Literature Review

Chapter Three:

Research

Methodology
Adequate presentation of critical reviews of literature relevant to the candidate's study Appropriate citation of sources of information used in the thesis or dissertation Indication of knowledge gaps from literature review which justifies the candidate's study Appropriate presentation of research design, including justifications for choosing the research design

Appropriate presentation of research design, including justifications for choosing the research design

Adequate description of the geographical area of the study, including justifications for choosing the area

Appropriate presentation of data generation procedures and tools and justifications for their choice

Appropriate presentation of data analysis plan (indicating how each set of data was analyzed)

Chapter Four:

Data Presentation,

Analysis, and

Discussion

Chapter Five:

Summary,

Conclusions and

The findings are presented according to the research objectives or questions or hypotheses

Adequate analysis and interpretation of the findings

Adequate discussion of the findings

Appropriate presentation of summary of the study and conclusion sections

Appropriate presentation of recommendations (reflecting the main findings of the study).

Recommendations

\section{Findings and discussion}

As pointed out in the introductory part of this article, this study sought to find out the nature and scope of challenges which faced postgraduate students in writing their dissertations and theses after conducting their studies. A total of 103 research reports, including 39 theses and 64 dissertations from three universities in Tanzania were reviewed. The findings are presented in Table 2 and the descriptions are presented in the following subsections according to chapters which were included in the reviewed theses and dissertations. 
Challenges of writing theses and dissertations among postgraduate students in Tanzanian higher institutions

Table 2

Findings on different aspects of the reviewed theses and dissertations

\begin{tabular}{lcc}
\hline \multicolumn{1}{c}{ Aspect } & Well-done & Not well-done \\
\hline Presentation of theoretical background of the study & $27 \%$ & $73 \%$ \\
Statement of the problem & $33 \%$ & $67 \%$ \\
Alignment of specific objectives of the study with the main objectives & $68 \%$ & $22 \%$ \\
Statements of specific objectives & $73 \%$ & $27 \%$ \\
Language clarity & $14 \%$ & $86 \%$ \\
Presentation of literature review & $31 \%$ & $69 \%$ \\
Citation of sources of information & $46 \%$ & $54 \%$ \\
Indication of knowledge gaps from literature review & $26 \%$ & $74 \%$ \\
Presentation of research design & $67 \%$ & $33 \%$ \\
Description of the geographical area of the study & $59 \%$ & $41 \%$ \\
Presentation of data generation procedures and tools & $63 \%$ & $37 \%$ \\
Presentation of data analysis plan & $60 \%$ & $40 \%$ \\
Presentation of findings & $82 \%$ & $18 \%$ \\
Analysis and interpretation of the findings & $37 \%$ & $63 \%$ \\
Discussion of the findings & $49 \%$ & $51 \%$ \\
Presentation of summary of the study and conclusions & $39 \%$ & $61 \%$ \\
Presentation of recommendations & $42 \%$ & $58 \%$ \\
\hline No. Nelo3
\end{tabular}

Note. $\mathrm{N}=103$

\subsection{Chapter one: Introduction}

This chapter had different names irrespective of the university where a candidate pursued the postgraduate program. While some candidates named this chapter as introduction, others named it background to the problem and others named the same as preamble. The variation in naming this chapter could be attributed to different orientations of the supervisors who had supervised the candidates. However, the contents of this chapter seemed to reflect on the same theme of giving background information to the problems regardless of how the chapter was named.

In this chapter, the researcher was, in the first place, interested to find out whether or not the candidates presented an adequate theoretical background to justify their studies. Regarding this aspect, the findings indicated that most of the students did not present theoretical backgrounds in a manner that justified the problems which prompted them to conduct studies. This was evident as $73 \%$ of the theses and dissertations indicated that the candidates had not clearly explained what was known and what was unknown about their topics of investigations before deriving knowledge gaps. The other proportion (27\%) of the theses and dissertations indicated that the candidates had, to a great extent, attempted to present an adequate theoretical background to justify their studies, as shown in Table 2 .

In the same chapter, the researcher was also interested to find out whether or not the statements of the problems indicated clearly what had prompted the candidates to conduct their studies. The findings on this aspect were as follows: First, all theses and dissertations had a section on the statement of the problem. However, the statements of problems in $67 \%$ of the reviewed theses and dissertations were not clearly presented. For example, the candidates did not indicate a good link between the background information and their statements of the problems. The remaining $33 \%$ of the theses and dissertations indicated that the candidates had, to some extent, attempted to state the problems rather satisfactorily. However, the statements of the problems were unnecessarily too long and some of them did not reflect the titles of the candidates' studies. In addition, the candidates did not indicate why particular problems of investigation were of importance. In other words, the candidates did not outline the basic rationale on which their studies were grounded.

The other aspect of investigation was whether or not the main objectives were in line with the specific objectives of the study. The findings showed that $68 \%$ of the theses and disertations indicated that the candidates 
had managed to allign the specific objectives with general objectives. On the other hand, $22 \%$ of the theses and dissertations indicated that there were disconnections between the specific objectives and general obectives. For example, some of the candidates had presented main objectives which did not refelect the titles of their studies. It is worth noting that the aims or objectives of the study are statements of what the study intends to accomplish. Whereas the general objectives are stated in general statements, giving the major purposes of the studies, the specific objectives are derived from the general objectives.

Morever, the researcher was also interested to find out whether or not the specific objectives were stated in an approriate manner. After reviewing the theses and dissertations, it was found that $73 \%$ of the theses and dissertations had, generally, well stated objectives as shown in Table 2. The objectives had action verbs which implied the kind of activities that would be accomplished to have the specific objectives achieved. On the other hand, $27 \%$ of the theses and dissertations had inappropriately stated specific objectives. For example, some candidates had duplicated objectives, resulting in redundant information. It was also observed that some candidates had stated objectives with more than one action verbs. This would be difficult for the candidates to assess the achievement of the objectives.

The last item of investigation in this chapter focused on whether or not the candidates used clear and understandable language. The findings on this aspect showed that more than $86 \%$ of the theses and dissertations had a couple of English language problems. The problems ranged from grammatical errors to stylistic shortcomings. For instance, in some theses and dissertations, the candidates misspelt words, wrote ungrammatical sentences, and presented contents in an incoherent manner. These are just some of the weaknesses related to language which were observed in the candidates' research reports. On the other hand, only $14 \%$ of the reports were found to have been presented in a clear and understandable language.

\subsection{Chapter two: Literature review}

In this chapter, a number of issues were observed as far the candidates' writing of theses and dissertations is concerned. In the first place, the researcher was interested to find out whether or not the candidates presented critical reviews of literature relevant to their studies. Regarding this aspect, $69 \%$ of the theses and dissertations indicated that the candidates were unable to present critical literature reviews. The findings revealed that in most of the reports, the arguments were loosely and uncritically presented. In most cases, the candidates failed to synthesize results from literature into a summary of what is and is not known. In addition, the candidates were expected to identify areas of controversy in the literature and formulate questions that would need further research. Therefore, it seemed that most of the candidates presented their literature reviews as 'shopping lists', implying that the reviews missed critical insights. Ideally, a literature review ought to be a piece of discursive prose as opposed to a mere list of descriptions or summaries from other peoples' works. The other proportion (31\%) of the theses and dissertations indicated that the candidates had to some extent attempted to evaluate the reviewed literature and show how the literature related to their studies.

The other aspect of review focused on the candidates' abilities to cite sources of information when writing this important chapter. In all the studied institutions, the candidates were supposed to abide by APA format for referencing and making citations. The findings revealed that a significant proportion (54\%) of the theses and dissertations showed that the candidates had weaknesses in making citations and those who seemed to abide by the guidelines accounted for $46 \%$ of the candidates. For example, while the listing of references was well done with most of the candidates, some citations in the texts were wrongly made. The case in point is one of the candidates who wrote Malekela (2003:104) instead of Malekela (2003, p.104). The other one wrote URT (1995:39) instead of $U R T(1995$, p.39). It was further revealed that tables and table captions were not in APA format and some references used in the texts did not appear in the lists of references. In addition, some theses and dissertations had too outdated references despite the presence of many up to date references. Therefore, it seemed that although there were guidelines for making citations and writing references, most of the candidates did not follow the guidelines. 
In the same chapter, the researcher was also interested to examine whether or not the candidates indicated gaps of knowledge when reviewing the literature. After scrutinizing the candidates' theses and dissertations, the findings revealed that $74 \%$ of the candidates were unable to derive knowledge gaps from the reviewed literature. The presentations of this chapter in different reviewed reports seemed to be rather too descriptive with little critical insights. The other proportion (26\%) of candidates' theses and dissertations showed that the candidates had managed to derive the knowledge gaps from the reviewed literature.

\subsection{Chapter three: Research methodology}

In this chapter, the researcher had two pertinent issues for examination regarding the ways in which the candidates wrote the chapter. First, the researcher sought to find out whether or not the candidates presented research methods and techniques they employed in conducting their studies. Secondly, the researcher was also interested in examining whether or not the candidates provided reasons or justifications for choosing such methods, techniques, tools, or procedures.

After reviewing the candidates' theses and dissertations, the findings were as follows: First, $67 \%$ of the theses and dissertations indicated that the candidates did not present their research designs appropriately. For example, most of the candidates mentioned research designs they claimed to have employed in their studies but they did not give justifications for the choice of such designs. On the other hand, 33\% of the theses and dissertations indicated that the candidates had provided reasons or justifications for choosing their research designs. A research design is a framework that specifies how each activity should be conducted to accomplish the research objectives. In other words, it is a detailed strategy for achieving research objectives. When the research design is not well presented, it becomes difficult for readers of any research report to understand how the study was conducted to arrive at the presented findings and conclusions.

The other aspect of investigation focused on the candidates abilities to describe geographical areas of their studies. In this section it was expected that the candidates would describe the geographical areas of their studies and explain why they conducted their studies in the identified areas. The findings indicated that $59 \%$ of the theses and dissertations had this section on description of the area of study wrongly presented. For instance, the majority of the candidates did not provide justifications for selecting certain areas for their studies. The case in point was one candidate who had this to write:

This study was conducted in Mbeya City which is in Mbeya region, one of the regions of Tanzania Mainland. The region is located in the South Western corner of the Southern Highlands of Tanzania.

This was the end of the candidate's description of the area of study. As it can be seen from the excerpt, the candidate had not explained why the study was conducted in Mbeya. Some other candidates identified the areas of their studies but the justifications provided were not sound. For example, there were candidates who gave reasons such as limited financial resources or accessibility to the identified areas as justifications for the choice of their geographical areas of studies. However, the findings further revealed that $41 \%$ of the theses and dissertations had this section satisfactorily presented. These had identified the areas and provided sound reasons for selecting such areas.

The researcher was also interested to find out whether or not the candidates were able to present the section on data generation procedures and tools in an appropriate manner. In this section, the candidates were expected to explain the procedures they followed in generating the data needed to accomplish their studies. In addition, they were also expected to explain the tools they used to generate the required data. The findings showed that $63 \%$ of the reviewed theses and dissertations had this section inappropriately presented. For example, most of the candidates listed the procedures they followed in generating the data. However, they did not make justifications for the choice of the data generation tools such as questionnaires, checklists, and interviews they had used. Only $37 \%$ of the dissertations and theses had this section adequately presented. 
The last aspect of investigation in this chapter focused on the candidates' abilities to present relevant information in the data analysis section. The findings indicated that $60 \%$ of the reviewed theses and dissertations had improperly written sections on data analysis. The theses and dissertations which indicated acceptable features of this section constituted $40 \%$ of the reviewed reports. For example, most of the reports showed that the candidates did not explain how each set of data was analyzed. The description was rather too general. In addition, for reports of quantitative studies, most of the candidates did not even mention the tools they used in analyzing the quantitative data. Ideally, this is the section where the candidates were expected to explain how they analyzed each generated set of data, including the tools used. For example, it was expected that if the candidate's study was more of a quantitative nature, they would explain that some statistical tools such as Regression Analysis, Chi Square Tests or ANOVA tests were ran in the analysis of the genarated data. On the other hand, if the study was of a qualitative nature, the candidate would, for instance, explain that thematic content analysis, which involves analyzing transcripts, identifying themes within those data and gathering together examples of those themes from the text, was used.

\subsection{Chapter four: Data presentation, analysis and discussion}

In this chapter, the candidates were expected to present their findings or results according to the advanced research objectives or questions or hypotheses. In addition, they were also expected to analyze and discuss the findings adequately.

After reviewing the documents, the findings revealed that $82 \%$ of the theses and dissertations had the findings presented according to the research objectives or questions or hypotheses while the reports with shortcomings in the presentation of the findings constituted only $18 \%$. Moreover, $63 \%$ of the reviewed theses and dissertations indicated that the candidates did not analyze the data adequately. Most of them had just presented the findings but they did not explain what the findings meant. Those who had attempted to explain what the presented findings meant in the context of their studies were $47 \%$. Regarding the discussion of the findings, the findings of this study showed that $49 \%$ of the candidates had attempted to discuss the findings of their studies. However, the presentations were in a very poor English language such that the candidates would have consulted editors or English language specialists to edit their research reports before submitting the same to the universities. On the other hand, $20 \%$ of the candidates had presented very short discussions while the analyses and interpretations were presented at length. The candidates who did not discuss the findings at all constituted $31 \%$. The discussion of findings is crucial because this is where the candidate's voice beyond the presented data and analysis is supposed to be revealed.

\subsection{Chapter five: Summary, conclusions, and recommendations}

In this chapter, candidates were expected to present their summaries, conclusions, and recommendations emanating from their studies. After reviewing the theses and dissertations, the following findings were evident: First, it seemed that the majority of the candidates confused between the conclusion of the study and summary of the study. This was typical in $61 \%$ of the reviewed documents. Most of the candidates summarized the findings of their studies and treated the same as conclusions. The remaining $39 \%$ of the candidates had indicated that they were knowledgeable on the difference between summary and conclusion of the study. However, most of the candidates did not present their conclusions by drawing main implications resulting from the presented data and discussion.

Secondly, it was also revealed that $58 \%$ of the candidates had not presented the recommendations appropriately. Most of them presented the recommendations in such a way that they lacked theoretical contribution to the topics under investigation. In addition, the recommendations did not reflect the findings of main themes of the studies and the derived conclusions. On the other hand, candidates who had attempted to present the recommendations as required constituted $42 \%$. 
The findings of this study suggest that the majority of students pursuing postgraduate programs in Tanzanian higher learning institutions face numerous problems in writing their theses and dissertations. The study confirms the findings of other studies conducted elsewhere (Wang \& Linda, 2008; Bitchener \& Basturkmen, 2006; Lessing \& Schulze, 2003), as pointed out in the literature review section of this article. This situation could be attributed to the following issues: First, given the trend of higher education students' enrolments in both undergraduate and postgraduate programs, this observation would not be surprising because the number of students pursuing postgraduate programs has increased tremendously in recent years. The increase in the number of students has essentially led to the increase in the number of students a supervisor is given to handle. By the time this study was being conducted, there were some faculty members in the institutions who had more than fifteen students to supervise their research works at both Master's degree and Doctorate levels. In other words, the increasing number of students seemed to be unproportional to the number of supervisors available in the institutions. With such a great number of students, it would be difficult for the supervisors to pay attention to all students and read their works critically. As a result, the students' research reports become substandard as it has been revealed in this study.

Secondly, the observation could also be attributed to the candidates' poor backgrounds in research report writing skills, which is also attributable to shortfalls in the contents and teaching of research methods courses at both undergraduate and postgraduate levels. As it has been revealed by the findings of this study, students seemed to have problems in writing their theses and dissertations in all chapters of their research reports. If the research methods courses were effectively taught, it was likely that some of the observed challenges would have been minimized.

\section{Conclusion and recommendations}

It is worth noting that writing a thesis or dissertation is not an easy task. It is essentially the product of effective training and proper guidance. As pointed out in the previous sections, the candidates whose research reports were reviewed in this study seemed to face numerous challenges in writing different chapters of their research reports. Most of the observed challenges seemed to have pedagogical orientations. In view of the observed challenges, the following recommendations are made: First, there is a need to review research methods courses offered in the universities, in terms of contents and teaching approaches. If this is properly done, the weaknesses indicated by candidates are likely to be minimized. Secondly, the universities should strive to subject all postgraduate students to academic writing training, with a special focus on how to write research reports.

\section{References}

Allison, D., Cooley, L., Lewkowicz, J., \& Nunan, D. (1998). Dissertation writing in action: The development of a dissertation writing support program for ESL graduate research students. English for Specific Purposes, 17, 199-217. http://dx.doi.org/10.1016/S0889-4906(97)00011-2

Bailey, K., 1994. Methods of social research. New York: The Free Press.

Bitchener, J., \& Basturkmen, H. (2006). Perceptions of the difficulties of postgraduate L2 thesis students writing the discussion section. Journal of English for Academic Purposes, 5(1), 4-18. http://dx.doi.org/10.1016/j.jeap.2005.10.002

Brailsford, I. P. (2010). Motives and aspirations for doctoral study: Career, personal, and inter-personal factors in the decision to embark on a history PhD. International Journal of Doctoral Studies, 5, 15-27.

Cadman, K. (1997). Thesis writing for international students: A question of identity? English for Specific Purposes, 16(1), 3-14.

Hartley, J. \& Jory, S. (2000). Lifting the vaail on the viva: the expereience of psychology PhD candiadates in the UK. Pschology Teaching Review, 9(2), 79-90.

Ho, A., Kember, D., \& Hong, C. (2012). What motivates an ever increasing number of students to enroll in part-time taught postgraduate awards? Studies in Continuing Education, 34(3), 319-338. http://dx.doi.org/10.1080/0158037X.2011.646979 
Komba, S. C.

Holbrook, A. Bourke, S., Lovat, T., Dally, T. (2004). Qualities and characteristics in the written reports of doctoral thesis examiners. Australian Journal of Educational and Developmental Psychology, 4, 126-145.

Huang, R. (2007). A Challenging but worthwhile experience: Asian international student perspectives of undertaking a dissertation in the UK. Journal of Hospitality, Leisure, Sport and Tourism Education, 6(1), 29-38. http://dx.doi.org/10.3794/johlste.61.130

Lessing A. C., \& Schulze, S. (2003). Lecturers' experience of postgraduate supervision in a distance education context. SAJHE/SATHO, 17(2), 159-168.

Lessing, A. C., \& Schulze, S. (2000). Postgraduate supervision in the faculty of education: Students' perceptions. Unpublished Research Report. Pretoria: UNISA.

Lessing, A. C., \& Schulze, S. 2002. Postgraduate supervision and academic support: students' perceptions. Journal of Higher Education, 16(2), 139-149. http://dx.doi.org/10.4314/sajhe.v16i2.25253

Mafa, O., \& Mapolisa, T. (2011). Supervisors' experiences in supervising postgraduate education students' dissertations and theses at the Zimbabwe Open University (ZOU). International Journal of Asian Social Science, 2(10), 1685-1697.

Murray, R. (2002). How to write a thesis. Buckingham: Open University Press.

Powers, J. (1994). What faculty say about working with graduate ESL writers. Paper presented at the Annual Meeting of Teaching English as a Second Language, Baltimore, MD.

Sokoine University of Agriculture. (2011). Regulations and guidelines for higher degrees. Morogoro: Directorate of Research and Postgraduate Studies, Sokoine University of Agriculture. Retrieved from http://www.suanet.ac.tz/phocadownload/regulation_guidelines2011.pdf

Taylor, S., \& Beasley, N. (2005). A handbook for doctoral supervision. London: Routledge.

Teowkul, K., Seributra, N. J. Sangkaworn, C., Jivasantikarn, C., Denvilai, S., \& Mujtaba, B. G. (2009). Motivational factors of graduate Thai students pursuing master and doctoral degrees in business. $R U$ International Journal, 3(1). Retrieved from http://citeseerx.ist.psu.edu/viewdoc/download?doi=10.1.1.464.3924\&rep=rep1\&type=pdf

University of Dar es Salaam. (2013). General regulations and guidelines for postgraduate programs. Dar es Salaam: Directorate of Postgraduate Studies, University of Dar es Salaam. Retrieved from http://www.suanet.ac.tz/phocadownload/regulation_guidelines2011.pdf

Wang, T., \& Li, L.Y. (2008). Understanding international postgraduate research students' challenges and pedagogical needs in thesis writing. International Journal of Pedagogies and Learning, 4(3), 88-96. http://dx.doi.org/10.5172/ijpl.4.3.88 